\section{Variations in psychiatric practice}

\author{
Neither unacceptable nor unavoidable, \\ only under-researched
}

SIMON GILBODY and ALLAN HOUSE

The White Paper A First Class Service (Secretary of State for Health, 1998) sets out the framework of government proposals for improving the quality of care in the National Health Service (NHS). A number of means are identified for achieving a change: setting national standards through a National Institute of Clinical Excellence (NICE) and National Service Frameworks; improving systems for local quality assurance through clinical governance, professional self-regulation and continuing medical education; and monitoring the implementation of standards using, among other mechanisms, a Commission for Health Improvement and a performance-management framework incorporating performance indicators.

There are parallels with past initiatives in the USA. For example, the Agency for Health Care Policy and Research (AHCPR) was established under public law in 1989 to improve standards through the compilation and dissemination of guidelines on best practice. Bodies such as the Joint Commission on Accreditation of Healthcare Organisations and the National Committee for Quality Assurance seek to maintain quality in hospitals, whose participation in state-managed care programmes (e.g. Medicaid) and private health maintenance organisations has become dependant upon adherence to such centrally produced guidelines (see Aday et al, 1998, for review).

A major theme underlying such initiatives is the reduction of "unacceptable variation in services across the country" (Secretary of State for Health, 1998), the rationale being that variation in clinical practice is undesirable because it reflects poor quality of care and inequality in service provision.

The term 'variation in practice' refers to two related phenomena: first, variation in the rates at which a specific intervention is used; second, variation in how an individual condition or clinical problem is managed. Variation in practice has been recognised for a long time. In the 1930s Glover demonstrated large differences in the rate of tonsillectomy in different parts of the UK (Glover, 1938), and more recently Wennberg \& Gittelsohn (1973) pioneered the 'small area variation study' into many common medical and surgical conditions. Some interventions are prone to unusually high variation - for example hysterectomy, tonsillectomy, prostatectomy, asthma, hypertension and peptic ulcer treatment. Others, such as hernia repair, hip repair and bowel surgery (Wennberg, 1984), are characterised by low variation. Variation in practice has been shown between countries and health care systems, between geographical areas within countries, between individual clinicians within the same area and by the same clinicians over time (see Roos et al, 1990, for review).

We know little about the extent to which psychiatric practice is subject to variation, because the topic is underresearched, although it might be supposed that the more we look for it, the more we will find. To give some examples: there are substantial differences in rates of admission from accident and emergency departments, and of psychosocial assessment, after attendance at hospital following deliberate self-harm (Gunnell et al, 1996; Kapur et al, 1998); variation in the indications for and mode of administration of electroconvulsive therapy has been demonstrated in successive audits (Pippard, 1992); and there is regional variation in the prescription of and access to new antipsychotics (Taylor et al, 1999).

If the eradication of variation in psychiatric practice is a central policy consideration, what are the implications? Should psychiatrists feel threatened or encouraged by the changes which are likely to ensue? We think there are reasons why they should at least be cautious.

\section{VARIATION IS NOT ALWAYS DUE TO IGNORANCE OF THE EVIDENCE}

Variation may simply result from differences in case mix in the services under study. Factors such as age, gender and social deprivation are also important determinants of the demands for and utilisation of health care. Once a rate of practice is standardised against social and case mix measures, and chance variation has been excluded (using statistical tests), a number of real causes of variation emerge, including the availability of resources, clinical judgement about the value of a treatment, patient expectation or demand, and prevailing custom (see McPherson, 1990, for review).

The ability of resources to influence medical practice is neatly summed up in Roemer's law, which states that "a built bed is a filled bed" (Roemer \& Shain, 1959). Supply-side factors, such as bed availability, staff provision, local provision of non-statutory agencies, waiting lists and ease of referral, will influence local practice and decision-making (see e.g. Logan, 1972).

However, unless there are severe constraints on resources, individual clinical style is potentially an important determinant of variation. Where there is no consensus about the indications for a procedure, variation in practice will occur. The highest rates of variation are seen in the management of conditions where the absence of consensus is due to there being no solid evidence about what works; this phenomenon has been termed "medical decision making under uncertainty" (Rizzo, 1993). A good example in psychiatry is the management of deliberate self-harm. Substantial variation in practice exists because there is no unequivocal evidence about the effectiveness of interventions (Hawton et al, 1998). In such cases variation does not represent wilful ignorance, but rather recourse to individual preference in the absence of convincing evidence to guide practice.

\section{VARIATION MAY NOT ALWAYS BE A BAD THING}

Practice variation in itself is unimportant, unless it can be shown that it has adverse consequences. Wennberg et al (1980) pioneered 'outcomes research', aimed at answering 
this question, mainly using large insurance claims databases in the USA. For example, the study of differences in rates of transurethral resection of the prostate for benign prostatic hyperplasia has shown that part of the variation is accounted for by overuse in some centres of surgery for early prostatism (Wennberg et al, 1987). However, 'outcomes research' has yielded few convincing examples of damaging variation in practice. A principal limitation of outcomes research is that the interpretation of its results is more difficult than is the case with more robust epidemiological research designs (Sheldon, 1994). Contrary to what US policymakers had hoped, the link between variation and inappropriateness has not been well established. The result is that for many conditions where practice variation is found, we do not know what represents the 'correct' rate and, therefore, what are the adverse effects of variation (Ham, 1988).

In the absence of evidence it is simply assumed that variation represents inappropriate care. Thus the under-use of an intervention may deny it to those who might benefit, while over-use is likely to give a procedure to those who might not benefit from it (or might be harmed by it) while perversely denying it to those who might benefit. Unfortunately, the assumption that variation is necessarily bad seems to be common sense but may not be true, and it certainly does not follow that imposing uniformity leads to better outcomes. In fact, there is some evidence that in areas which exhibit low variations in practice there may be more inappropriate care as treatment becomes unresponsive to the individual patient or population (Roos \& Roos, 1982; Roos et al, 1990). Despite this, the managed care movement in the USA has used demonstrations of variation to try to drive down health care spending by stipulating that interventions should only be offered at the lower end of the range of rates of intervention (Aday et al, 1998).

In summary, a demonstration of variation at a macro level is not a clearcut indicator that care is inappropriate. Wide variations which appear at the aggregate level often disappear when individual data are analysed. A demonstration of practice variation should prompt research to investigate the causes of this variation, rather than efforts to eradicate it.

\section{TOP-DOWN APPROACHES TO CHANGING PRACTICE ARE LARGELY INEFFECTIVE}

Suppose we accept that there are some clinical practices in which variation should be reduced. What then is the best way of achieving that aim? The proposed approach of the White Paper (Secretary of State for Health, 1998) is essentially top-down, with nationally prepared guidelines produced by NICE, implemented (but not developed) through local agreement, and ultimately enforced by the Commission for Health Improvement. To take one example, NICE will become the umbrella organisation for the existing Confidential Inquiry into Suicide and Homicide by People with a Mental Illness, which will make recommendations on national practice and policy to help reduce deaths, and these recommendations will be applied nationally.

Any attempt to address practice variation is going to depend upon an effective professional behaviour change strategy, and that involves more than generating guidelines or monitoring practice. For example, audit by itself is only minimally effective in changing clinical practices (Thomson et al, 1998a), whereas the presentation of a key research or policy message by a local opinion leader can be effective (Thomson et al, 1998b). A successful clinical practice guideline will be based upon methodologically valid and critically evaluated evidence, but it should also have been generated with the involvement of its eventual users, taking into account local circumstances (Effective Health Care, 1994, 1999).

In other words, it is local factors (such as prevailing custom, prevailing consensus and strong local opinion leaders) which are most important in determining actual clinical practice (Greer, 1988). Clinicians in one locality are unlikely to act on information-research summaries or practice guidelines - that are national in origin, without local endorsement. Hence, national demonstrations of practice variation will not influence clinical policy unless the message is clearly perceived as relevant to local clinicians. By the same token, national guidelines have very little effect on actual practice at a local level (Effective Health Care, 1999). Even in the USA, where care is highly prescriptive, driven by guidelines and subject to cost containment by reimbursement, variation in psychiatric practice is widespread (e.g. Fortney et al, 1996).
In the UK there are national (consensusbased) guidelines on the management of deliberate self-harm (Department of Health and Social Security, 1984), and it should come as no surprise to learn that they are largely ignored (Hawton \& James, 1995). Two national audits of the practice of electroconvulsive therapy have not led to uniformity of delivery, despite guidelines on practice which are endorsed by the Royal College of Psychiatrists (Pippard, 1992; Freeman, 1995).

\section{IMPOSING UNIFORMITY IS NOT THE SAME AS ENSURING BEST PRACTICE}

Even if uniformity of practice can be enforced, it is not clear that what will result is best practice.

The US experience of generating evidence-based guidelines is instructive. The AHCPR has produced a number of psychiatric guidelines, most recently on the management of schizophrenia (Lehman, 1998). Of the 28 recommendations that are offered (that is, those for which there was sufficient high-quality evidence), the majority related to pharmacological interventions (Hargreaves, 1998), reflecting the pharmacological emphasis of much research in psychiatry. Study of the Cochrane Database of Reviews reveals a similar bias towards pharmacological treatments (Cochrane Database of Systematic Reviews, 1999).

It might be relatively easy to produce evidence-based guidelines for drug treatments in psychiatry, whereas any attempt to produce evidence-based guidelines in more complex areas - such as health care policy, psychosocial interventions or risk management - is likely to be unsuccessful. 'No evidence of effectiveness' is not the same thing as 'evidence of no effectiveness', but if practice has to be based only upon published evidence for what works, the stage is set for more emphasis on drug treatments.

However, even in those areas where there is sufficient evidence to guide practice, a single rate at which an intervention is offered is unlikely to be best for everyone - that is, 'appropriateness' will vary by patient and by context.

\section{CONCLUSIONS}

The current political imperative to reduce practice variation in care raises some 
uninviting possibilities for psychiatry. Pressure for uniformity may squeeze out harmless (or even beneficial) variation, in the name of an evidence base which is both poor-quality and biased. The pressure to be seen to be staying 'on message' may lead to over-enthusiastic promotion of an unstructured assortment of guidelines based on weak evidence or consensus, coupled with bureaucratic monitoring of practice. At the same time, ironically, the preoccupation with nationally set guidelines, and with the machinery to monitor their implementation, may lead to failure to ensure that sensible and desirable practice is adopted at a local level.

Of course, we must support the principle of evidence-based practice. However, the main lesson to be learned from systematic reviewing in the field of psychiatry is just how poor most of the evidence really is. What we need more than populist 'quality improvements' is good-quality research, which should be less directed than it is now by the short-termism of competitive research empires and by the needs of the pharmaceutical industry. The NHS research and development programme provides a major opportunity in this respect. Only with the results of such research in hand can we reasonably insist on adherence to a programme aimed at removing variation in psychiatric practice.

\section{ACKNOWLEDGEMENT}

We are grateful to Professor Trevor Sheldon, of the York Health Policy Group, for his comments.

\section{REFERENCES}

Adry, L. A., Begley, C. E., Lairson, D. R., et al (1998) Evaluating the Healthcore System: Effectiveness. Efficiency and Equity. Chicago, IL: Health Administration Press.

Cochrane Database of Systematic Reviews (1999) In The Cochrane Library, Issue I. Oxford: Update Software.

Department of Health and Social Security (1984)

The Management of Deliberate Self Harm. London: DHSS

Effective Health Care (1994) Implementing Clinical Guidelines: Con Guidelines be Used to Improve Practice? York: University of York.

SIMON GILBODY, MRCPsych, NHS Centre for Reviews and Dissemination, University of York; ALLAN HOUSE, MRCPsych, Division of Psychiatry and Behavioural Sciences, University of Leeds

Correspondence: Dr Simon Gilbody, NHS Centre for Reviews and Dissemination, University of York. York YOIO 5DD. Tel: 01904 433634; Fax: 01904 433661; e-mail: smg5@york.ac.uk

(First received 28 April 1994, accepted 9 June 1999)

_ (1999) Getting Evidence into Proctice. York: University of York.

Fortney, J. C., Booth, B. M. \& Smith, G. R. (1996) Variation among VA hospitals in length of stay for treatment of depression. Psychiatric Services, 47. 608-613.

Freeman, C. P. (ed.) (1995) The ECT Hondbook. The Second Report of the Royal College of Psychiatrists' Special Committee on ECT. Council Report CR39. London: Royal College of Psychiatrists.

Glover, J. A. (1938) The incidence of tonsillectomy in school children. Proceedings of the Royal Society of Medicine, 31, 1219-1236.

Greer, A. L. (1988) The state of the art versus the state of the science: the diffusion of new medical technologies into practice. International joumal of Technology Assessment in Healthcore, 4, 5-26.

Gunnell, D., Brooks, J. \& Peters, T. (1996) Epidemiology and patterns of hospital use after parasuicide in the south west of England. Journal of Epidemiology and Community Health, 50. 24-29.

Ham, C. (1988) A review of the literature. In Health Care Variations: Assessing the Evidence. London: The King's Fund Institute.

Hargreaves, W. A. (1998) Commentary on: The schizophrenia Patient Ouctomes Research Team (PORT) treatment recommendations. Schizophrenia Bulletin, 24 23-24.

Hawton, K. \& James, R. (1995) General hospital services for attempted suicide: a survey of one region. Health Trends, 27, 18-21.

- , Arensman, E., Townsend, E., et al (1998) Deliberate self-harm: systematic review of efficacy of psychosocial and pharmacological treatments in preventing repetition. British Medical journal, 317. $441-447$.

Kapur, N., House, A., Creed, F., et al (1998) Management of deliberate self poisoning in adults in four teaching hospitals: descriptive study. British Medical journal, 316, 831-832.

Lehman, A. F. (1998) Translating research into practice: The schizophrenia Patient Outcomes Research Team (PORT) treatment recommendations. Schizophrenia Bulletin, 24, 1-10.

Logan, R. (1972) Dynamics of Medical Care. London London School of Hygiene and Tropical Medicine.
McPherson, K. (1990) Why do variations occur? In The Challenges of Medical Proctice Variotions (eds T. F. Andersen \& G. Mooney). London: Macmillan.

Pippand, J. (1992) Audit of electroconvulsive therapy in two National Health Service regions. British Journol of Psychiatry. 160, 621-637.

Rizzo, J. A. (1993) Physician uncertainty and the art of persuasion. Social and Scientific Medicine. 37. 145I-1459.

Roemer, R. E Shain, M. (1959) Hospital costs relate to the supply of beds. The Modern Hospital, 92, 71-73.

Roos, N. P. \& Roos, L. L. (19e2) Surgical rate variations: do they reflect the health or the socioeconomic characteristics of the populations? Medical Core, 20, 945-958.

Roos, L. L., Brazauskas, R., Cohen, M. M., of of (1990) Variations in outcomes research. In The Challenges of Medical Practice Variations (eds T. F. Andersen \& G. Mooney). London: Macmillan.

Secretary of State for Health (1988) A First Class Service: Quality in the New NHS. London: HMSO.

Sheldon, T. A. (1994) Please bypass the PORT. British Medical Journal, 309, 142-143.

Taylor, D., Mir, S., Mace, S., ef al (1999) A national survey of anti-psychotic prescribing. Primary Core Psychiatry, in press.

Thomson, M. A., Oxman, A. D., Davis, D. A., et of (1998) Audit and feedback to improve health professional practice and health care outcomes (Cochrane Review). In The Cochrone Library, Issue 4. Oxford: Update Software.

_, _ , Haynes, R. B., et al (1998b) Local opinion leaders to improve health professional practice and health care outcomes (Cochrane Review). In The Cochrane Librory, Issue 4. Oxford: Update Software.

Wennbers, J. E. (1984) Dealing with medical practice variations. Heolth Affoirs, 3, 6-32.

- Gittelsohn, A. (1973) Small area variations in healthcare delivery: a population based health information system can guide planning and regulatory decision-making. Science, 182, 1102-1109.

_, Bunber, J. P. \& Barnes, B. (1980) The need for assessing the outcome of common medical practices. Annual Review of Public Health, I. 277-295.

_, Roos, N., Sola, L., et ol (1987) Use of claims data systems to evaluate healthcare outcomes: mortality and re-operation following prostatectomy. Journal of the American Medical Association, 257, 933-936. 